\title{
Experiências e desafios para a preservação digital de mídias sociais
}

\author{
Laura Vilela Rodrigues Rezende* \\ Dalton Lopes Martins**
}

Artículo recibido:
7 de mayo de 2018
Artículo aceptado:
5 de febrero de 2019

Artículo de revisión

\section{Resumen}

Estudio de análisis cualitativo, en el que se presenta el mapeo de relevantes experiencias gubernamentales internacionales en la preservación digital de contenidos generados en medios sociales en Inglaterra, Estados Unidos y Australia. Los análisis se basaron en características tecnológicas, que abarcan cuestiones relacionadas con la plataforma de medios sociales, solución tecnológica de recolección de datos, estrategia de preservación y formato de los datos almacenados. Las características contextuales buscaron identificar cuestiones relacionadas con los metadatos para garantizar la procedencia, autenticidad, gestión de derechos y tipos

\footnotetext{
* $\quad$ Faculdade de Informação e Comunicação, Universidade Federal de Goiás, Brasil lauravil.rr@gmail.com / laura_rezende@ufg.br ** Faculdade de Ciência da Informação, Universidad de Brasilia, Brasil dmartins@gmail.com / daltonmartins@unb.br INVESTIGACIÓN BIBLIOTECOLÓGICA, vol. 33, núm. 80, julio/septiembre, 2019, México,
ISSN: $2448-8321$ pp. 31-56
} 
de acceso. Es posible concluir que existe un aumento en el uso de medios sociales en el ámbito gubernamental, resaltando, además, que los marcos regulatorios archivísticos deben ser considerados en las acciones de preservación de estos contenidos. La instantaneidad comunicacional y participación del ciudadano en los medios sociales han exigido al Estado una actuación rápida y transparente. Las plataformas de medios sociales no demuestran compromiso con cuestiones vinculadas a la recolección y archivado de contenidos para la preservación. Los resultados señalan que existen varias similitudes en las experiencias gubernamentales en cuestión. Las iniciativas comenzaron hace más de cinco años y utilizaron las principales plataformas de medios sociales existentes. Las experiencias utilizan como estrategia de preservación la emulación.

Palabras clave: Preservación Digital; Redes Sociales; Web 2.0; Esfera Gubernamental.

Experiences and challenges for the digital preservation of social media

Laura Vilela Rodrigues Rezende and Dalton Lopes Martins

\section{Abstract}

A qualitative study that presents the mapping of relevant international governmental experiences of digital preservation of contents generated in social media in the countries: England, the United States and Australia. The analyzes were based on technological characteristics, which cover issues related to the social media platform, data collection technology, preservation strategy and format of stored data. The contextual characteristics sought to identify metadata related issues in order to guarantee provenance, authenticity, rights management and access types. It was possible to conclude that there is an increase in the use of social media in the governmental scope, noting that archival regulatory milestones should be considered in the preservation actions of these contents. Communicational instantaneity and citizen participation in social media have required the State to act quickly and transparently. The social media platforms do not 
demonstrate commitment to issues related to the collection and archiving of contents aimed at preservation. The results indicate that there are several similarities in the governmental experiences in question. The initiatives started more than 5 (five) years ago and use the main existing social media platforms. Experiments use emulation as a preservation strategy.

Key Words: Digital Preservation; Social Media; Web 2.0; Governamental Sphere.

\section{INTRODUÇÃO}

$\mathrm{O}$ cenário tecnológico mundial se apresenta repleto de recursos que têm proporcionado ao cidadão experiências de uso cada vez mais enriquecedoras, especialmente quanto à utilidade e capacidade de participação social no que é possível se fazer. Observa-se um crescente incremento na interação entre pessoas, especialmente pela criação e compartilhamento de conteúdos digitais, tendo as ferramentas colaborativas como pano de fundo, trazendo inovações, tanto no modo de produção quanto naquilo que pode ser produzido, em todos os segmentos e as áreas do conhecimento.

Constata-se uma proliferação de novos serviços que envolvem diversas possibilidades de interação social em torno de objetos digitais, agregando novas camadas de informações registrando essas interações, que hoje se tornam fundamentais ao serem utilizadas por algoritmos que calculam a relevância social desses objetos e os organizam de forma sistemática para apresentação nas interfaces de busca. Do ponto de vista informacional, novas questões e desafios surgem relacionados com a preservação digital, considerando o aumento da complexidade das informações de relevância que hoje devem ser consideradas para que se possa caracterizar de forma completa os objetos digitais e as relações sociais ao seu entorno.

Este contexto anteriormente descrito, se refere à segunda geração da Internet conhecida como web 2.0, projetada para facilitar as relações sociais, o compartilhamento da informação, a interoperabilidade e a comunicação (Tripathi e Kumar, 2010: 195). A web 2.0 pode ser entendida como uma nova geração de serviços e produtos, e não uma revolução tecnológica. No início, a web 1.0 foi marcada pela disponibilidade de informações estáticas para simples consulta e leitura. Os usuários acessavam os conteúdos de forma 
passiva, não podiam estabelecer uma interação ou participação na criação dos mesmos. A maioria dos serviços não era gratuita, sendo necessário adquirir licenças para acessá-los (Coelho, 2009: 1). A web 2.0 sucinta na quebra deste paradigma conceitual, podendo ser considerada como a nova fase de comunidades e serviços fundamentados na ideia da web como plataforma, onde o ambiente virtual proporciona colaboração e interação dos conteúdos oferecidos com seus usuários.

Trata-se de uma revolução comportamental em que prevalece a participação e colaboração dos usuários no tocante ao uso das informações. Segundo O'Reilly (2005), o termo web 2.0 pode ser utilizado para identificar novos avanços de enfoque qualitativo na Internet que antes não existiam. Esta geração da Internet, também chamada de Web Social, é marcada pela presença de ferramentas interativas que permitem uma participação e colaboração ativa dos usuários que geram e recebem conteúdos dinâmicos personalizados sob demanda.

As mudanças sociais produzidas pelo uso intensivo da web 2.0, quando observadas em conjunto, apresentam novos fenômenos sociais e tecnológicos que não apenas se tornam mais complexos por conta da escala e volume com que ocorrem, como inovam na produção de novas maneiras de relacionamento, trabalho e produção informacional, gerando a necessidade de se repensar várias questões relacionadas aos modos tradicionais de produção da informação, questionando e colocando em análise os papéis e saberes estabelecidos. As novas formas de trabalho em rede, com o surgimento de novos atores que colaboram com a produção de informação de relevância, somadas às inovações produzidas por novos algoritmos sociais, que recombinam a participação dos usuários e a informação de novas maneiras, como é possível se observar em experiências como a Wikipedia (2017), Uber (2017), Waze (2017), (Netflix, nd), Amazon (2017) (Google, nd), entre outros, trazem à tona questões relacionadas à necessidade de rever e repensar muitos dos modos de gestão contemporânea da informação. Entende-se que é exatamente nessas novas aberturas de possibilidades e no espaço produzido pelo surgimento do novo, que é possível propor novos olhares para os múltiplos fenômenos informacionais do século XXI.

Neste contexto, também conhecido como web social, surge um questionamento em relação à memória destes materiais, que possuem particularidades que precisam ser consideradas quando se trata de preservação. Arquivar o material gerado no contexto da web 2.0, trará para a humanidade registros relevantes do momento atual e abre questões que se tornam de extrema relevância na contemporaneidade relacionada à preservação de novos 
tipos de objetos digitais. O desaparecimento da rede social Orkut, criada pelo Google em 2002 e com duração de 12 anos, sendo encerrada em 2014, com suas funcionalidades dinâmicas e ficando seu conteúdo disponível para "download" [baixar] até meados de 2016, é considerado um caso clássico de perda de conteúdo web criado de maneira colaborativa. Durante os dois anos que a rede esteve disponível para consulta, os processos de extração de conteúdo não eram considerados fáceis, especialmente por conta do grande volume de dados, além da problemática do que se pode considerar um dos elementos mais importantes em redes sociais: as conexões, que ficavam fortemente comprometidas ao serem reconstituídas após as tentativas de extrações, apesar de se considerar que eram ambientes preparados e que contavam com recursos técnicos profissionais para a pesquisa.

Considera-se o Orkut uma ferramenta com papel extremamente importante nos processos de socialização em redes digitais no Brasil, sendo um dos países mais atuantes e participativos em termos mundiais. Cabe o seguinte questionamento: o patrimônio cultural ali produzido e armazenado em suas bases de dados também não faz parte do patrimônio cultural brasileiro, servindo de referência como fonte de pesquisa e, sobretudo, como dinâmica social de articulação em rede e como campo de produção de capital social e cultural de uma nação? Que impactos o seu desaparecimento produz em nossa memória? Seriam essas questões de interesse de uma política pública para a memória digital em pleno século XXI e mesmo para a pesquisa científica na área da Ciência da Informação? Nossas instituições custodiais estão preparadas para lidar com a arquitetura de socialização de produção informacional em rede? Tais perguntas demandariam processos de pesquisa amplos e complexos, indo muito além da proposta deste artigo, mas que cabe aqui serem pontuadas por terem sido inspiradoras desta pesquisa.

O presente estudo tem seu enfoque no mapeamento e análise de experiências internacionais que estão hoje realizando ações de preservação digital de conteúdos gerados em mídias sociais. Entende-se aqui, que conhecer essas experiências, avaliar suas potencialidades e pontos críticos é um passo fundamental como ponto de partida para a pesquisa científica no referido tema. Visando delinear algumas respostas possíveis para este questionamento, este estudo apresentará uma revisão de literatura relacionada à preservação digital e conceitos ligados à web 2.0, além de trazer um panorama de iniciativas ao redor do mundo que desenvolvem ações de arquivamento para a preservação de conteúdos de mídias sociais. 


\section{Preservação digital: definiçôes}

Diante da realidade de que as novas tecnologias implantadas na sociedade moderna vieram a culminar em um forte crescimento de informações em meio digital, sobretudo aquelas produzidas por diversas instâncias de relevante importância para manutenção das atividades cotidianas, a United Nations Educational, Scientific and Cultural Organization (Unesco) apresentou em sua conferência geral, $32^{a}$ reunião em Paris no ano de 2003, um documento intitulado "Carta para preservação do patrimônio digital". A referida carta foi elaborada pela Unesco (2003) e apresentada aos países membros, em virtude da necessidade de se pensar práticas voltadas para a preservação do patrimônio cultural da humanidade, representado através da diversidade de documentos digitais produzidos nestes países, em especial, a carta considera de grande relevância a adoção de medidas preventivas em virtude do risco eminente que corre este bem, devido à instabilidade e obsolescência cada vez mais acelerada dos suportes da tecnologia de informação (ti), no que diz respeito às soluções de hardware e software suplantadas pela mesma.

Priorizando a temática, em 2012, a Unesco publicou a Declaração de Vancouver, intitulada "A memória do mundo na era digital: digitalização e preservação". Este relevante documento, sinaliza novamente para a emergência do tema de preservação digital, trazendo questões ligadas aos direitos humanos dos cidadãos.

Ao abordar o tema da preservação digital, a Unesco considera para a elaboração destes dois documentos, alguns fatores impactantes nesta temática, dentre os quais figuram: o risco de desaparecimento da herança cultural das nações; a necessidade de conservação do patrimônio universal, representados pelos produtos do conhecimento humano, sobretudo o patrimônio documental; a crescente produção, distribuição e uso dos recursos informacionais em formato eletrônico, constituindo novo tipo de patrimônio, o digital; o reconhecimento de que o acesso a este vasto contingente de informação proporcionará maiores oportunidades a toda humanidade, possibilitando a criação, comunicação, assim como a troca de experiências; a urgente necessidade de se promover a preservação do patrimônio digital ao redor do mundo, em benefício das gerações atuais e futuras; os documentos nativos digitais e digitalizados devem ter a mesma importância na definição de padrões e modelos que garantam acesso contínuo.

No Brasil, o Conselho Nacional de Arquivos (Conarq), baseado nas recomendações da Unesco, veio por meio de carta aberta, convocar "os setores públicos e privados, envolvidos com a produção e proteção especial dos 
documentos em formato digital, a envidarem esforços para garantir sua preservação e acesso contínuo [...]" especialmente por considerar que esta produção digital representa um patrimônio fortemente ameaçado de extinção e desprovidos de confiabilidade e que sua preservação em benefício das gerações atuais e futuras é uma preocupação urgente no mundo inteiro" (Conarq, 2016: 1).

Devido à grande relevância e em função do alcance que se obteve com as propostas sobre o tema da preservação digital iniciadas pela Unesco, inúmeras instituições e pesquisadores se posicionaram a favor da necessidade de proporcionar as condições necessárias e seguir as recomendações oferecidas pela literatura para, de fato estabelecer ações e práticas voltadas para efetivar a preservação digital. Conforme vem acrescentar Arellano (2004: 15) "a aplicação de estratégias de preservação para documentos digitais é uma prioridade, pois sem elas não existiria nenhuma garantia de acesso, confiabilidade e integridade dos documentos ao longo prazo".

Ao conteúdo digital, alvo de preservação, atribui-se o nome de objeto digital. Conforme interessa a este estudo desmistificar, os objetos digitais consistem em recursos de informação que possam ser representados por uma sequência de dígitos binários, sejam eles nascidos em formato digital, ou mesmo convertidos para este formato, por meio de recursos como a digitalização, processo em que, pelos meios análogos, obtêm-se a representação destes recursos em meio digital. Ferreira, esclarece ser a preservação digital:

o conjunto de atividades ou processos responsáveis por garantir o acesso continuado a longo-prazo à informação e restante património cultural existente em formatos digitais. A preservação digital consiste na capacidade de garantir que a informação digital permanece acessível e com qualidades de autenticidade, suficientes para que possa ser interpretada no futuro, recorrendo a uma plataforma tecnológica diferente da utilizada no momento da sua criação (Ferreira, 2006: 20).

Conforme observado em vários trabalhos sobre a guarda da informação em formato digital, nota-se que apenas promover a guarda destes documentos em soluções tecnológicas e aplicações de software, não tem sido suficiente para assegurar a longevidade de acesso e preservação destes documentos resguardados. Tal fato se deve à constatação certa de que, tanto os novos recursos de software quanto as novas tecnologias representadas pelo hardware se tornam obsoletas em um tempo relativamente curto, estando ainda suscetíveis à danos e acidentes não previstos, e que podem encurtar ainda mais sua perspectiva de funcionamento em relação ao tempo de uso estimado. 
Depois de percorridas as devidas ressalvas em relação aos requisitos de armazenamento de conteúdo em formato digital, sobretudo em função dos obstáculos a serem transpostos para que se possa garantir a preservação destes documentos, assim como um acesso continuo aos mesmos ao longo do tempo, convêm mencionar que tal prática apresenta inúmeras vantagens para as unidades que a adotam, sendo as principais: o acesso dinâmico e remoto aos conteúdos, dispensando-se para tanto a necessidade de consulta aos seus representantes em meio físico. Dentre as desvantagens apresentadas pelos documentos em formato digital, Ferreira apresenta aquela que mais contribui para justificar a adoção de uma estratégia de preservação:

o material digital carrega consigo um problema estrutural que coloca em risco a sua longevidade. Embora um documento digital possa ser copiado infinitas vezes sem qualquer perda de qualidade, este exige a presença de um contexto tecnológico, para que possa ser consumido de forma inteligível por um ser humano. Esta dependência tecnológica torna-o vulnerável à rápida obsolescência a que geralmente a tecnologia está sujeita (Ferreira, 2006: 17-18).

Desta forma, uma vez identificadas as particularidades dos objetos digitais em sua relação de dependência com os recursos de software e hardware, assim como as necessidades de acesso e preservação da informação neles contidas, a etapa que se procede consiste na definição das estratégias de preservação a serem adotadas, que deverão por sua vez ser formalmente explicitadas por meio de um plano ou da política de preservação digital.

\section{Estratégias para preservação digital}

As estratégias para preservação digital constituem métodos a serem adotados, diante de situações visando agir de maneira preventiva ou corretiva, frente aos objetos digitais a serem preservados. Segundo Thomaz e Soares, estas estratégias podem ser agrupadas em:

estratégias estruturais e operacionais. As estratégias estruturais dizem respeito aos investimentos ou esforços iniciais por parte da instituição, preparando seu ambiente para o processo da preservação digital. As estratégias operacionais, por sua vez, representam as atividades ou medidas concretas de preservação digital (Thomaz e Soares, 2004: 4). 
Considerando que inúmeras são as técnicas utilizadas frente a um número igualmente grande de formatos de arquivo digital, assim como de tecnologias para seu armazenamento, elaborou-se o quadro 1 visando melhor ilustrar algumas das principais práticas recomendadas na literatura especializada, conforme o nível de estratégia utilizado.

\begin{tabular}{|c|c|c|}
\hline Nivel de estratégia & Estratégia & $\begin{array}{c}\text { Definição/ } \\
\text { Recomendação }\end{array}$ \\
\hline \multirow[t]{5}{*}{ Estratégias estruturais } & Adoção de padrões & $\begin{array}{l}\text { Adoção de formatos de } \\
\text { arquivos abertos que } \\
\text { contenham amplo acesso, } \\
\text { assistência técnica, } \\
\text { suporte e estabilidade a } \\
\text { longo prazo. }\end{array}$ \\
\hline & Elaboração de manuais & $\begin{array}{l}\text { Manuais que possuem } \\
\text { a função de orientação } \\
\text { quanto ao tratamento } \\
\text { de objetos digitais e } \\
\text { o gerenciamento dos } \\
\text { riscos envolvidos na sua } \\
\text { preservação. }\end{array}$ \\
\hline & $\begin{array}{l}\text { Metadados para } \\
\text { preservação digital }\end{array}$ & $\begin{array}{l}\text { Informações estruturadas } \\
\text { sobre dados utilizados } \\
\text { neste contexto para } \\
\text { descrever objetos digitais, } \\
\text { atuando de maneira a } \\
\text { facilitar a pesquisa e a } \\
\text { identificação de suas } \\
\text { fontes de informação; } \\
\text { gerenciar seu fluxo dentro } \\
\text { de processos; representar } \\
\text { suas estruturas para } \\
\text { possibilitar o acesso. }\end{array}$ \\
\hline & $\begin{array}{c}\text { Montagem } \\
\text { de infraestrutura para } \\
\text { preservação digital }\end{array}$ & $\begin{array}{l}\text { Consiste do conjunto com- } \\
\text { posto por infraestrutura } \\
\text { de hardware, software e } \\
\text { pessoas. }\end{array}$ \\
\hline & $\begin{array}{l}\text { Formação de uma } \\
\text { rede de relações }\end{array}$ & $\begin{array}{l}\text { Desenvolvimento de re- } \\
\text { lações com corporações, } \\
\text { federações, consór- } \\
\text { cios, entre outros. Tal } \\
\text { estratégia visa consolidar } \\
\text { associações e alianças } \\
\text { com parceiros especia- } \\
\text { lizados e com interesses } \\
\text { benéficos ao processo } \\
\text { de preservação digital a } \\
\text { longo prazo. }\end{array}$ \\
\hline
\end{tabular}




\begin{tabular}{|c|c|c|}
\hline \multirow[t]{5}{*}{$\begin{array}{l}\text { Estratégias } \\
\text { operacionais }\end{array}$} & $\begin{array}{c}\text { Escolha do meio } \\
\text { de armazenamento }\end{array}$ & $\begin{array}{l}\text { Decisão sobre fatores que } \\
\text { impactam direta ou indi- } \\
\text { retamente em recursos, } \\
\text { tais como: disponibilidade } \\
\text { de acesso, velocidade } \\
\text { do dispositivo de leitura, } \\
\text { entre outros. Estes fatores } \\
\text { incluem: capacidade de } \\
\text { leitura/gravação, capaci- } \\
\text { dade de armazenamento, } \\
\text { compatibilidade com o } \\
\text { hardware/software já } \\
\text { instalado, durabilidade, } \\
\text { capacidade de detecção } \\
\text { de falhas, facilidade de } \\
\text { manuseio, etc. }\end{array}$ \\
\hline & Migração & $\begin{array}{l}\text { Conjunto de atividades } \\
\text { para copiar, converter } \\
\text { ou transferir, periodi- } \\
\text { camente a informação } \\
\text { digital existente em uma } \\
\text { determinada geração } \\
\text { de tecnologia para as } \\
\text { gerações subsequentes. }\end{array}$ \\
\hline & Emulação & $\begin{array}{l}\text { Criação de um novo } \\
\text { software que imita o } \\
\text { funcionamento do antigo } \\
\text { hardware e/ou software } \\
\text { visando reproduzir seu } \\
\text { comportamento. }\end{array}$ \\
\hline & $\begin{array}{l}\text { Impressão em papel } \\
\text { ou microfilme }\end{array}$ & $\begin{array}{l}\text { Técnica a ser utilizada em } \\
\text { objetos digitais estáticos } \\
\text { com o objetivo de prolon- } \\
\text { gar a expectativa de vida } \\
\text { destes documentos. }\end{array}$ \\
\hline & $\begin{array}{l}\text { Conservação } \\
\text { da tecnologia }\end{array}$ & $\begin{array}{l}\text { Técnica que consiste em } \\
\text { manter a tecnologia que } \\
\text { originou os objetos digitais } \\
\text { para que permaneçam } \\
\text { utilizáveis. }\end{array}$ \\
\hline
\end{tabular}

Quadro 1. Estratégias de preservação digital. Fonte: Adaptado de Thomaz e Soares (2004).

Ao que se aplicam os esforços em promover a preservação dos documentos em formato digital, tem-se que inúmeras técnicas se demonstram eficazes na manutenção do contexto de armazenamento, tanto no que diz respeito à solução tecnológica adotada quanto em relação às aplicações proporcionadas 
pelo software, contudo cabe lembrar que estas práticas devem ser apoiadas por uma gama maior de ações, que devem ser desenvolvidas pelos administradores destas informações, juntamente com suas comunidades de produtores e usuários, em um esforço conjunto para se alcançar a regularidade da preservação, evitando-se ao máximo o acionamento de ações corretivas.

Um ponto importante na busca pela preservação à longo prazo dos recursos digitais, consiste em apoiar as práticas descritas à adoção dos metadados, em suporte a descrição do contexto em que se insere o objeto digital a época de sua inclusão em determinado banco de dados. "É preciso chamar a atenção para a importância de informar o contexto do objeto digital a ser registrado (e preservado) para que, dessa maneira, futuros usuários possam entender o ambiente tecnológico no qual ele foi criado" (Arellano, 2004: 15).

Especificamente tratando-se de metadados que apoiam a preservação digital, Sayão (2010: 1) especifica que "esse tipo de metadados [...] tem como função instruir e documentar os processos de preservação digital de longo prazo, garantindo que os conteúdos digitais possam ser acessados e interpretados no futuro".

Considerando-se que os recursos tecnológicos, assim como os formatos de armazenamento e ainda os próprios documentos digitais podem vir a sofrer alterações, intencionais ou não, assim como exigências ou restrições relativas aos direitos autorais, exigindo estas particularidades, a adoção de novos padrões, formatos e tecnologias, faz-se necessário a prática de registro destas informações por meio de metadados específicos para esta ocasião. Desta forma, os metadados de preservação possuem sua importância assumida pois,

todas essas estratégias para alcançarem seus objetivos, dependem fortemente da captura, criação e manutenção de vários tipos de dados que informem sobre histórico, características técnicas, estruturas, dependências e alterações sofridas pelo objeto digital. São esses dados que viabilizarão o pleno acesso e permitirão a recriação e a interpretação da estrutura e do conteúdo da informação digital ao longo do tempo. Para tal, eles são estruturados na forma de metadados, compondo o que chamamos de "metadados de preservação" (Sayão, 2010: 10).

Frente à amplitude de fatores e ações que, visando garantir a preservação dos recursos digitais que precisam ser documentados por meio dos metadados específicos para esta finalidade, observa-se que dentre os principais aspectos a serem relatados estão:

1) Proveniência: os metadados de preservação devem registrar informações sobre a história do objeto desde sua origem, traçando a sua cadeia de custódia e de propriedade; 
2) Autenticidade: os metadados de preservação devem incluir informações suficientes para validar que o objeto é de fato o que diz ser e que não sofreu alterações intencionais ou não não documentadas;

3) Atividades de preservação: os metadados de preservação devem documentar as ações tomadas ao logo do tempo para preservar o objeto digital e as consequências dessas ações sobre aparência, usabilidade e funcionalidades do objeto;

4) Ambiente técnico: os metadados de preservação devem descrever as dependências técnicas necessárias para a apresentação e uso dos objetos digitais, tais como hardware, sistema operacional e software de aplicação;

5) Gestão de direitos: os metadados de preservação devem registrar todos os itens relacionados às questões de propriedade intelectual que limitem as ações de preservação, de disseminação e uso por parte de usuários de hoje e do futuro (Lavoie e Gartner, 2005: 5).

\section{Mídias sociais e a construção colaborativa da herança cultural digital}

Segundo Torres (2009), mídias sociais são páginas da web que possibilitam ao usuário atuar, não apenas como um mero leitor, e sim como produtor, curador e consumidor da informação, com a liberdade de criar, recomendar e trocar conteúdo com os outros usuários.

De acordo com as mudanças sofridas pela cultura online, os usuários de maneira geral desempenham um papel fundamental na criação e publicação de conteúdos web, especialmente nas mídias sociais. Lampert e Chung afirmam que, normalmente Conteúdos Gerados pelo Usuário (ugc, por sua sigla em Inglês) englobam a criação e contribuição voluntária de conteúdos por meio de interações entre usuários comuns, que não são profissionais da informação (Lampert e Chung, 2011: 75).

O manual Preservation of Web Resources Handbook traz ponderações acerca da "fluidez" que muitas vezes caracteriza o conteúdo da web 2.0. Tal característica pode dificultar a identificação do ponto em que o conteúdo postado foi concluído e, por conseguinte estaria pronto para ser arquivado (ULCC e UKOLN, 2008).

Em relação ao arquivamento de conteúdos de mídias sociais, alguns desafios podem ser assim relatados conforme Pennock: 
O arquivamento do Twitter, por exemplo, não deve considerar somente os tweets de forma isolada. Tratam-se de conversas estabelecidas. Sendo assim, pensar em se arquivar uma simples página do Twitter, significa considerar que, somente um lado da conversa está sendo guardado. Como estabelecer limites para se definir com coerência uma coleção do Twitter? Seria necessário capturar todas as respostas de perfil de usuário, além deste perfil na íntegra? Seria necessário arquivar os perfis dos respondentes visando garantir informações suficientes sobre o contexto de um conteúdo específico? Baseando-se na relevância dos links para o Twitter, todos os links que foram compartilhados por um perfil também deveriam ser arquivados? Como o arquivo poderia garantir consistência temporal entre os links e o conteúdo presentes nestes sites, dada a curta duração de um link no Twitter? Definir os limites de uma rede social envolve questões bem mais complexas do que aparentemente parece ser algo simples (Pennock, 2013: 13).

Outro fator complicador são as questões ligadas às permissões. Qualquer site com conteúdo gerado por usuários distintos apresenta o desafio de solicitar ao detentor do conteúdo a autorização para arquivamento. Trata-se de uma empreitada demorada e às vezes até impossível de ser realizada (Pennock, 2013: 13).

Diante do desafio de se definir estruturas, padrões e ferramentas tecnológicas que sirvam como referência para a preservação de conteúdos de mídias sociais, várias são as tentativas de discutir e implementar o arquivamento destes materiais visando acesso a longo prazo. A seguir um recorte possível de experiências de arquivamento de conteúdo visando a preservação.

\section{Metodologia e ANÁlise dos Resultados}

O presente estudo se caracteriza com abordagem qualitativa, com seu enfoque no mapeamento e análise de ações de preservação digital de conteúdos gerados em mídias sociais. Buscou-se com este mapeamento conhecer essas experiências, avaliar suas potencialidades e pontos críticos com base nas seguintes características de Lavoie e Gartner (2005):

- Tecnológicas:

- Qual a plataforma de mídia social a ser preservada;

- Qual a solução tecnológica para a coleta dos dados das mídias sociais e a utilização de serviços de terceiros.

- Qual estratégia de preservação utilizada;

- Qual o formato de armazenamento dos dados coletados. 
- Contextuais:

- Identificar se os metadados coletados garantem: proveniência, autenticidade, gestão de direitos, e tipos de acesso (público ou restrito à uma comunidade específica) conforme listados pelos autores (Lavoie e Gartner 2005, 5).

Um documento a ser destacado como fonte de informação para o presente estudo é o relatório do Digital Preservation Coalition Technology Watch Report, de fevereiro de 2016 (Thomson, 2016), que apresenta como tema central a preservação de conteúdos de mídias sociais. Esta série de relatórios provê uma introdução avançada ao tema em questão, buscando abordar tópicos relevantes para o sucesso da coleta da memória digital, garantindo acesso futuro. $\mathrm{O}$ referido relatório abrange a existência de experiências governamentais e acadêmicas de preservação digital de mídias sociais. Para este estudo optou-se por apresentar a esfera governamental destas experiências. Algumas iniciativas listadas a seguir foram extraídas deste relatório uma vez que se trata de uma publicação relevante e pioneira na temática em questão. Outras experiências apresentadas foram originadas de buscas realizadas nas bases de dados Scopus e Web of Science e na web utilizando-se os termos: "web archiving", "digital preservation", social media" e "social repository".

Os relatos de iniciativas governamentais apresentados a seguir visam preservar os conteúdos oficiais produzidos em mídias sociais. Buscou-se identificar iniciativas geograficamente distribuídas em continentes distintos visando ampliar o escopo geográfico do que tem sido realizado no âmbito governamental relacionado à preservação deste tipo de conteúdo. Os países selecionados, Inglaterra, Estados Unidos e Austrália sempre foram considerados pioneiros em se tratando de preservar conteúdos digitais produzidos. Isto pode ser comprovado uma vez que, no momento da redação do presente estudo, dezembro de 2017 a janeiro de 2018, não foram identificadas outras experiências governamentais de arquivamento e preservação de conteúdos de mídias sociais.

\section{Experiência britânica de arquivamento de conteúdos de midias sociais}

O Arquivo Nacional inglês em parceria com a Internet Memory Foundation (IMF), iniciou em 2011 um projeto piloto para capturar comunicações oficiais realizadas pelo governo nas mídias sociais, a saber: Twitter e YouTube. Neste projeto, intitulado “The National Archives' UK Government Social 
Media Archive”, foram desenvolvidas soluções escaláveis para a captura de perfis governamentais definidos previamente em horários regulares, garantindo que este conteúdo permaneça disponível, mesmo se depois estas contas destes perfis originais desaparecerem (National Archives, 2014).

Este estudo piloto desenvolveu uma política de seleção e abordagem técnica, que permite aos Arquivos Nacionais e IMF realizarem os procedimentos de aquisição, curadoria e redistribuição destes registros atendendo aos marcos legais e políticos relevantes, além de satisfazer às necessidades informacionais da comunidade de usuários do United Kingdom Government Web Archive (UKGWA, nd). Esta abordagem forneceu à equipe do projeto entendimento de selecionar somente conteúdos e metadados publicados pelas contas do governo central oficial, visando atender ao Public Records Act 1958 (legislation.gov.uk, nd) que obriga a preservação de todos os registros informacionais governamentais, independente do formato e simultaneamente evitar o risco de infringir os direitos autorais regidos pela Crown Copyright seção 163 do Copyright, Designs and Patents Act 199 (legislation.gov.uk, nd).

Conforme relatado por Thomson (2016), UKGWA e IMF se empenharam para desenvolver soluções tecnológicas apropriadas para que o arquivamento das mídias sociais fosse o mais automatizado possível. Para isto, o projeto piloto foi baseado em Application Program Interface (API). A iniciativa criou soluções para garantir que somente dados e metadados relevantes seriam coletados pela API do Twitter. O conteúdo coletado e arquivado pelo ukgwa pode ser acessado por meio de uma simulação da interface do Twitter graças à utilização do Twitter Archive Reader desenvolvido pela IMF, além de ser possível também realizar o download destes tweets (Thomson, 2016: 31). Os links para sites governamentais citados nos tweets, os quais possuem um endereço abreviado que fazem parte da plataforma, são convertidos para a URL original. Vale ressaltar que, segundo o documento Operational Selection Policy (OSP 27) - UK Central Government Web Estate (National Archives, 2014), links para sites fora do escopo governamental previamente definido, re-tweets e respostas ou conversas que abrangem tweets de outras contas não são arquivados. Obedecendo a política de uso do Twitter, o laboratório não pode armazenar estes dados coletados em dispositivos na nuvem e nem os compartilhar com outras instituições.

Os vídeos do Youtube podem ser reproduzidos no site do UKGWA pelo JW Player (2017), um reprodutor de vídeos de código aberto. Considerando a questão da confiança por parte dos usuários do projeto, o ukgwa disponibiliza os metadados originais, incluindo as tags e descritores de vídeos. 


\section{Experiências americanas de arquivamento de mídias sociais}

Os Estados Unidos da América possuem a lei intitulada O Ato de liberdade de informação (The Freedom of Informacion Act, FOIA), que exige que os registros de ações e comunicações do governo federal devem ser arquivados e disponibilizados para acesso público, quando solicitadas (USDJ, 2016). Existem várias iniciativas americanas de arquivamento de conteúdos de mídias sociais, especialmente na esfera governamental de seus estados. Buscou-se apresentar aqui duas iniciativas em esfera nacional, que contemplassem aspectos distintos da temática, a saber: Mapeamento de melhores práticas de arquivamento de conteúdo de mídias sociais em agências governamentais e arquivamento de conteúdo de mídias sociais oficiais da presidência da república.

\section{Best Practices Study of Social Media Records Policies}

Em 2011, a organização educacional sem fins lucrativos The American Council for Technology (ACT), fundada em 1979, cujo foco é auxiliar o governo americano a adquirir e usar recursos de tecnologia da informação efetivamente, por meio do seu Grupo de Interesse Compartilhado em Colaboração e Transformação (C\&T SIG) realizou um estudo que propõe discussões acerca do uso de mídias sociais visando auxiliar o governo e cidadãos a se conectarem de maneira mais próxima, colaborativa e aberta. O estudo realizou entrevistas com membros de dez (10) agências governamentais sobre os processos de gerenciamento arquivístico que contemplam o uso de mídias sociais. A maioria das agências utilizam as principais ferramentas comerciais de mídias sociais. O grupo identificou que, apesar do uso ativo de ferramentas de mídias sociais apresentar desafios no tocante ao armazenamento de registros, permite o surgimento de melhores práticas já implementadas por algumas agências ou que precisam ser implementadas por outras visando vencer os desafios identificados (ACT, 2011: 4).

Desafios identificados na pesquisa:

- Dificuldades em se definir os conteúdos de mídias sociais como registros arquivísticos.

- A maioria dos conteúdos de mídias sociais é de domínio público e, sendo assim não estão sob o controle das agências governamentais dificultando a sua captura. 
- O uso automatizado de metadados gerados pelas ferramentas para marcação de conteúdos de mídias sociais dificulta a recuperação. Por causa disto, todas as agências entrevistadas estão utilizando métodos manuais de adicionar metadados nos conteúdos de mídias sociais.

- Agendamento e disponibilidade de conteúdos de mídias sociais: a lacuna identificada nas questões ligadas ao controle de conteúdo de mídias sociais dificulta o agendamento e disponibilidade dos dados para serem coletados.

- Ações educacionais: Ações continuadas de formação são essenciais para uma implementação de políticas de armazenamento de conteúdos de mídias sociais bem-sucedida (ACT, 2011: 5).

Melhores práticas identificadas na pesquisa:

- A equipe que realiza o arquivamento de mídias sociais deve ser formada por arquivistas ou membro da equipe de arquivamento, gestores web, gestores de mídias sociais, membro da equipe de tecnologia da informação e outros atores relevantes neste contexto de produção e divulgação de conteúdo.

- Agências devem recorrer a variados recursos informacionais ao criar políticas e implementar melhores práticas no uso de mídias sociais, especificamente em relação ao seu arquivamento.

- Faz-se necessário a definição de papéis e responsabilidades em relação ao uso e armazenamento de mídias sociais.

- Os Sistemas de Gestão de Conteúdos (ecm) devem contemplar as mídias sociais e oferecer requisitos para captura, definição de metadados e agendamento do arquivamento deste tipo de conteúdo (ACT, 2011: 5).

As recomendações listadas poderão servir de embasamento inicial para instituições que estão iniciando seus projetos de arquivamento de conteúdos de mídias sociais visando à preservação.

\section{The Obama White House-Social Media Archive}

O Presidente Barack Obama e a Casa Branca utilizaram as mídias sociais para interagir com o público americano e internacional. O presidente decidiu preservar todas as interações destas mídias por meio do The Obama White House-Social Media Archive. O arquivo possui mais de 250,000 posts, fotos 
e vídeos compartilhados por mais de 100 perfis oficiais de mídias sociais ( $\mathrm{Fa}$ cebook, Twitter, Instagram, Flickr, Google+, Pinterest). O conteúdo deste arquivo é público e disponível na íntegra para todos visando a transparência e preservação histórica das interações ocorridas no período entre 2009 e 2017 (The Obama White House-Social Media Archive, 2017).

$\mathrm{O}$ arquivamento das mídias sociais é feito pela empresa ArchiveSocial, especialista em preservação deste tipo de conteúdo. São utilizadas API ["Application Programming Interface"] da própria mídia social para a realização do processo automático de captura, de registros completos em formato bruto e nativo incluindo todos os metadados, podendo ser gerados em xml ou json, dependendo da mídia. Após serem coletados, os registros recebem uma autenticação digital temporal que obedece ao padrão RFC 3161 (Adams, 2001) o qual estabelece diretrizes que permitem evidenciar que um dado em ambiente digital existia antes de um determinado momento conferindo-lhe autenticidade uma vez que é possível garantir sua identidade (garantia de o dado é único) e integridade (garantia de que o dado não sofreu alterações de forma e conteúdo).

O sistema de arquivamento ArchiveSocial após capturar os dados, processa-os visando armazená-los em uma base confiável do ponto de vista da preservação digital, ou seja, garantindo acesso futuro, e emulando um sistema que simula todo o ambiente e contexto originais incluindo a resolução de imagens e a conversão de URL. Os dados são preservados conforme foram criados, mantendo interface interativa com sua aparência nativa garantindo a mesma experiência de uso original em formato JSON [JavaScript Object Notation]. Obedecendo a política de uso da plataforma de mídia social, não é possível armazenar estes dados coletados em dispositivos na nuvem e nem compartilhar com outras instituições. A ferramenta ArchiveSocial possui uma API de interface de visualização de dados onde é possível recuperar as atualizações de status, todos os comentários, imagens em tamanho original, assistir a vídeos, além de vários outros recursos como sendo registros independentes visando garantir o acesso a todo o conteúdo original oficial gerado nas mídias sociais durante os dois mandatos do presidente.

\section{Experiência australiana de arquivamento de mídias sociais}

Os registros públicos da Austrália são regidos por várias leis, incluindo o The Public Records Act 2002 (Queensland Government, nd) e o Archives Act 1983 (Federal Register of Legislation, 2014). Ambos definem o registro como 
sendo um documento ou objeto em qualquer formato, incluindo o eletrônico que tem sido mantido para acesso ao longo prazo. O Arquivo Nacional da Austrália publicou um manual de aplicação de sua legislação ao conteúdo das mídias sociais produzido por órgãos governamentais australianos. Conforme o Arquivo Nacional, os registros criados como resultados do uso de mídias sociais estão sujeitos às mesmas exigências comerciais e legislativas que os registros criados por outros meios. $\mathrm{O}$ manual também explica porque estes registros não podem ser mantidos somente em suas redes sociais e devem sim ser capturados e armazenados pelas agências (governamentais ou legislativas) que os criaram. Existe também um documento que institui um modelo de política de mídia social, disponível para ser utilizado por todos os órgãos governamentais que desejam arquivar o conteúdo de suas mídias sociais (Social Media Records in Austrália, 2017).

O Arquivo Nacional da Austrália possui em seu site a indicação de modelos de políticas de uso e preservação de mídias sociais, disponíveis para encorajar as agências governamentais que queiram preservar este tipo de conteúdo produzido no âmbito oficial. Além disto, inclui também links para iniciativas em curso nos seguintes estados: Australian Capital Territory, New South Wales, South Austrália, Victoria e Western Austrália. A estrutura tecnológica que vem sendo utilizada na Austrália e está divulgada é a da "Archive Social” (2017), seguindo as mesmas especificações técnicas já informadas anteriormente. Não foi possível identificar iniciativa de arquivamento do governo federal deste país. O que foi informado pelo Arquivo Nacional da Austrália é que as ações de arquivamento têm ocorrido de forma descentralizada e independente.

Embora se considere relevante apresentar a experiência australiana em arquivamento e preservação de dados de mídias sociais, a ausência de uma iniciativa governamental federal australiana divulgada detalhadamente culminou na escolha por excluir este país das análises comparativas que serão apresentadas a seguir. 


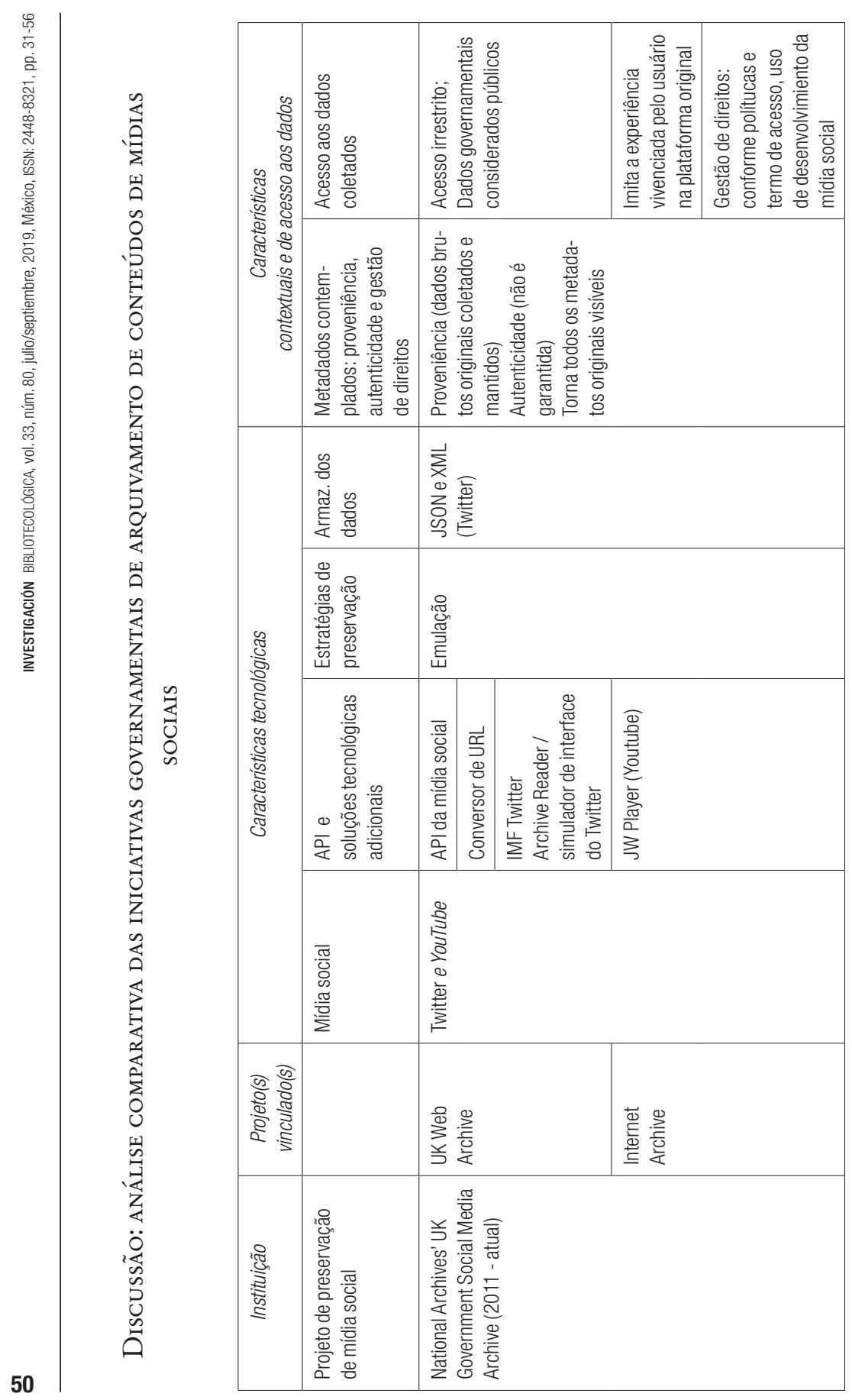


EXPERIÊNCIAS E DESAFIOS PARA A PRESERVAÇÃO DIGITAL...

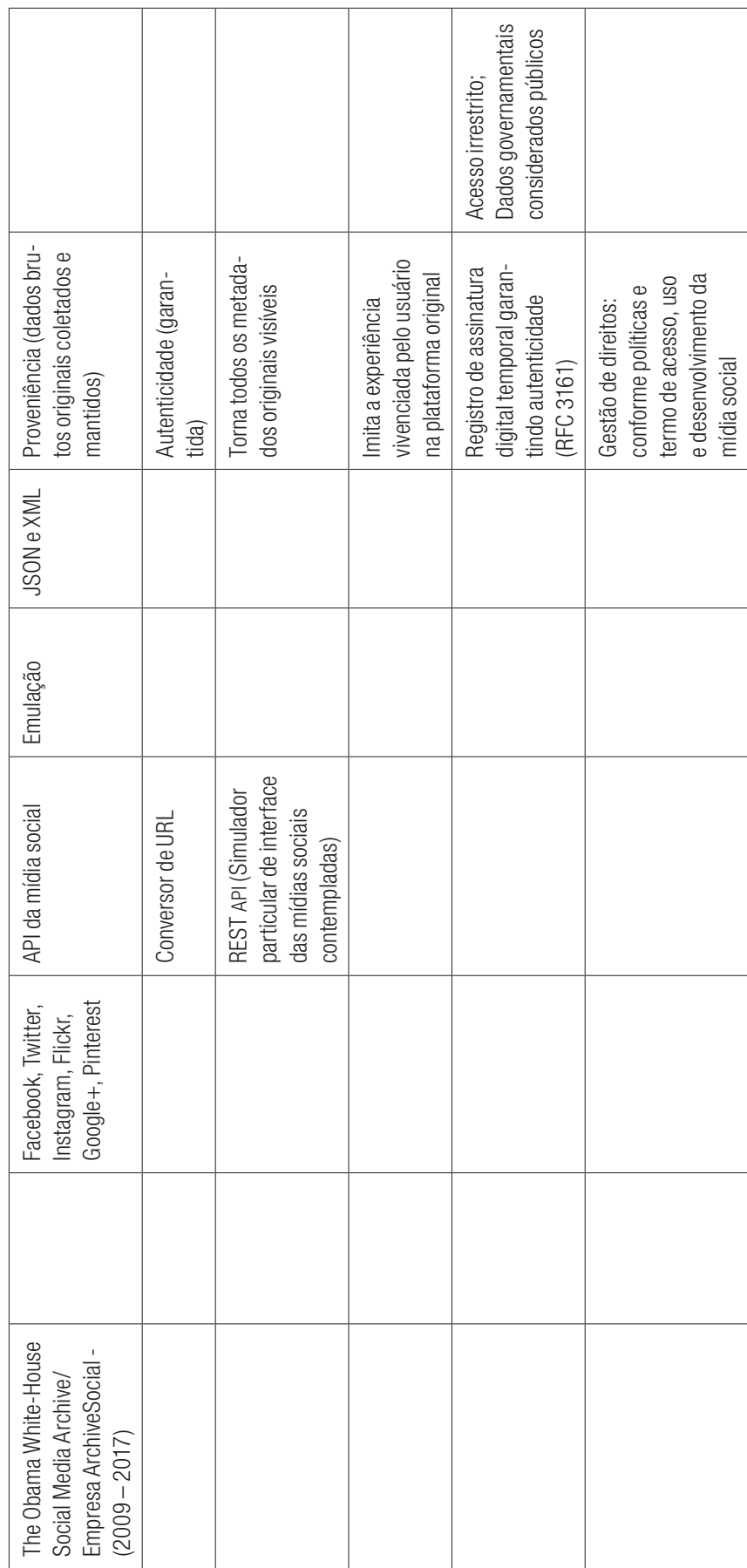


O Quadro 2 demonstra que existem várias semelhanças nas experiências governamentais em questão. As duas iniciativas tiveram início há mais de 5 (cinco) anos e utilizam as principais plataformas de mídias sociais existentes. As experiências utilizam como estratégia de preservação a emulação que, segundo Ferreira, sua grande vantagem está na capacidade de preservar, com um elevado grau de fidelidade, as características e as funcionalidades do objeto digital original (Ferreira, 2006: 33-34). Thomaz e Soares (2004) afirmam que a emulação é a criação de um novo software que imita o funcionamento do antigo hardware e/ou software para reproduzir seu comportamento.

Um ponto a se considerar é que ambas as experiências utilizam a API de cada plataforma de mídia social para a captura dos dados além de também utilizarem sua própria API para a imitação da interface nativa original e reproduzir a experiência de utilização do usuário. Tal fato demonstra que a rigidez e obsolescência das normas das plataformas de mídias sociais relacionadas ao acesso, uso e desenvolvimento de software acabam por dificultar a liberdade de captura, armazenamento e uso dos dados. Vale citar também que existe um escopo pré-definido de perfis das mídias sociais que serão coletados, tornando o contexto destas experiências mais simples, em se tratando de questões ligadas ao acesso e uso dos dados.

Em relação aos metadados contemplados pelos projetos de armazenamento dos dados das mídias sociais, os de proveniência foram identificados uma vez que os dados brutos originais são coletados e mantidos em formato original. Já os metadados de autenticidade só são garantidos na experiência americana uma vez que ela utiliza o registro de assinatura digital temporal (RFC 3161). Um ponto relevante e crucial que deveria ser considerado é o momento da criação destes dados. As plataformas de mídias sociais não preveem a criação de metadados ligados à preservação digital deste tipo de dados, isto significa que muitos destes descritores são atribuídos manualmente pela equipe dos projetos de arquivamento, após serem coletados, dificultando o trabalho de seleção e classificação dos mesmos. No tocante ao acesso aos dados coletados, estes são considerados públicos por serem provenientes de perfis governamentais. Isto simplifica as questões referentes à privacidade no acesso e uso dos dados coletados.

\section{Considerações Finais}

O uso de conteúdo das mídias sociais é algo recente e que tem ganhado relevância por parte de instituições governamentais e das entidades que têm 
a função de custódia e preservação da herança cultural da humanidade, a saber: bibliotecas, arquivos e museus além de instituições acadêmicas. Vários são os desafios que se relacionam com a prática do arquivamento e preservação deste tipo de conteúdo, dentre eles, é possível destacar as mudanças contínuas nas plataformas de mídias sociais, especialmente relacionadas ao surgimento de novas aplicações e desaparecimento de outras, conferindo volatilidade a este tipo de conteúdo. O uso colaborativo dificulta o planejamento do arquivamento destes dados, uma vez que é preciso se considerar questões de permissões, direitos de acesso e vínculos estabelecidos durante as trocas de informações. Os aspectos que demarcam o contexto das postagens, tais como a temporalidade, autoria, tipificações e temática dos conteúdos também devem ser considerados, uma vez que determinarão a seleção do que realmente deve ser preservado. Além disso, as conexões sociais estabelecidas em torno dos objetos digitais também devem ser preservadas, a exemplo de uma postagem no Facebook, seria necessário preservar quem curtiu essa postagem, comentou, compartilhou, entre outros eventos que compõem este tipo de conteúdo.

A transparência nas ações de preservação de conteúdos de mídias sociais deve ser um fator relevante, não somente por questões éticas, mas também visando conferir confiança aos usuários destas mídias, em se tratando da coleta, arquivamento e preservação de seus dados. É preciso especificar como e por quem os dados coletados serão utilizados, principalmente em se tratando de pesquisas científicas.

Observou-se nos relatos de experiências de arquivamento de conteúdos de mídias sociais que os marcos regulatórios arquivísticos dos países devem ser prioritariamente considerados no planejamento destas ações. Os países que ainda não fazem menção de maneira explícita a este tipo de conteúdo em seus marcos regulatórios arquivísticos devem se adequar visando conferir legalmente relevância para este tipo de documento. $\mathrm{O}$ protagonismo do Estado em relação à preservação da herança cultural de seu povo abrange desafios quanto à sua atuação diante de novos conteúdos e formatos informacionais. A instantaneidade comunicacional e participação do cidadão nas mídias sociais têm exigido do Estado uma atuação rápida e transparente respondendo aos anseios da sociedade. $\mathrm{O}$ registro e arquivamento da atuação governamental nas mídias sociais visando acesso futuro se faz necessário no intuito de garantir que este acervo se torne acessível para gerações vindouras de cidadãos.

Independente da finalidade de se preservar os conteúdos de mídias sociais, é prudente afirmar que esta nova prática social de comunicação colaborativa tem contribuído para a avalanche informacional incessante, a qual 
desafia os mecanismos criados até então para coleta e arquivamento desta massa documental. Relevante deve ser a atuação curatorial nos projetos de preservação, visando selecionar e então coletar o que de fato deve ser guardado.

Observa-se que as plataformas existentes de mídias sociais mais utilizadas não demonstram comprometimento com questões ligadas à coleta e arquivamento de conteúdos gerados nestes ambientes visando à preservação. Observa-se também a inexistência de conceitos e práticas arquivísticas por parte dos sistemas que mantém estas plataformas proprietárias. Em geral, parece correto afirmar que as políticas de uso e arquivamento dos sistemas destas empresas não acompanharam a evolução vivenciada nas experiências dos usuários em se criar e compartilhar conteúdo.

A existência de uma equipe multidisciplinar que possa implementar projetos voltados para a preservação de conteúdos de mídias sociais também é algo essencial para o sucesso destas ações. Os arquivistas, bibliotecários e museólogos, com todo o seu arcabouço teórico e prático de arquivamento informacional, juntamente com os profissionais de tecnologia da informação (web designer, gestores de mídias sociais, dentre outros) devem se unir para que possam reinventar práticas tradicionais de arquivamento visando abarcar os conteúdos complexos das mídias sociais. Assim, estes ambientes informacionais poderão garantir que os preceitos de preservação façam parte de todo o ciclo de vida do documento, desde sua criação até o seu arquivamento ou descarte.

\section{REFERÊNCIAS}

Adams, C. 2001. "Sociedade da internet". Acessado em 10 de agosto de 2017, <https://www.ietf.org/rfc/rfc3161.txt

Amazon. 2017. Brasil (website). Acessado em 10 de agosto de 2017, <https://www. amazon.com/>.

ArchiveSocial. 2017. "Registros de mídias sociais na Austrália”. Durham, Carolina do Norte (EUA) (website). Acessado em 10 de agosto de 2017, <https://archivesocial.com/social-media-records/australia/>.

Arellano, Miguel Angel. 2004. "Preservação de documentos digitais". Ciência da Informação 33, n. 2: 15-27, <http://revista.ibict.br/ciinf/article/view/1043/1113>.

Coelho, Helena Sofia Felisberto. 2009. "A Web 2.0 nas bibliotecas universitárias portuguesas: Um estudo da implementação do paradigma da biblioteca 2.0”. Doutorado, Universidade de Lisboa, <http://repositorio.ul.pt/handle/10451/400>.

Conselho Nacional de Arquivos (Conarq). 2016. "Ata da 85 $5^{a}$ Reunião Plenária Ordinária do Conarq". Brasília: Ministério da Justiça, <http://conarq.gov.br/reunioes-plenarias/620-ata-da-85-reuniao-plenaria-ordinaria-do-conarq.html>. 
Federal Register of Legislation. 2014. “Archives Act 1983”. Australian Government (website). Acessado em 10 de agosto de 2017, <https://www.legislation.gov.au/ Details/C2014C00417>.

Ferreira, Miguel. 2006. "Introdução à preservação digital: Conceitos, estratégias e actuais consensos”. Guimarães, Lisboa: Escola de Engenharia da Universidade do Minho, <http://repositorium.sdum.uminho.pt/bitstream/1822/5820/1/livro. pdf $>$.

Google Brasil. Nd. (Website). Acessado em 10 de agosto de 2017, <https://www.google.com.br/webhp?hl=pt-BR\&tab=ww $>$.

JW Player. 2017. "A plataforma de vídeo mais poderosa e flexível”. Página Principal. Nova York (website). Acessado em 10 agosto de 2017, <https://www.jwplayer. $\mathrm{com} />$.

Lampert, Cory K. e Chung, Su Kim. 2011. "Strategic Planning for Sustaning User-Generated Contente in Digital Collections". Journal of Library Inovation 2, n. 2: 74-93, <http://digitalscholarship.unlv.edu/lib_articles/407/>.

Lavoie, Brian e Richard Gartner. 2005. "Technology Watch Report: Preservation Metadata". Dublin, Ohio: OCLC, <http://www.dpconline.org/docman/technology-watch-reports/88-preservation-metadata/file>.

Legislation.gov.uk. Nd. "Copyright, Designs and Patents Act 1988”. National Archive. Reino Unido (website). Acessado em 10 de agosto de 2017, <http://www.legislation.gov.uk/ukpga/1988/48/section/163>.

Legislation.gov.uk. Nd. "Public Records Act 1958". National Archive. Reino Unido (website). Acessado em 10 de agosto de 2017, <http://www.legislation.gov.uk/ ukpga/Eliz2/6-7/51>.

National Archives. 2014. "Operational Selection Policy OSP27: UK Central Government Web Estate”. Londres (website). Acessado em 10 de agosto de 2017, <http:// www.nationalarchives.gov.uk/documents/information-management/osp27.pdf >.

Netflix Brasil. Nd. (Website). Acessado em 10 agosto de 2017, <https://www.netflix. $\mathrm{com} / \mathrm{br} />$.

O'Reilly, Tim. 2005. "What is Web 2.0?: Design Patterns and Business Models for the Next Generation of Software”. Acessado em 10 de agosto de 2017, <http:// oreilly.com/web2/archive/what-is-web-20.html>.

Pennock, Maureen. 2013. "Web Archiving”. Digital Preservation Coalition 13, n. 1. Acessado em 10 de agosto de 2017, <http://dx.doi.org/10.7207/twr13-01>.

Queensland Government. Nd. "In Force Legislation”. Queensland, Austrália (website). Acessado em 10 de agosto de 2017, <https://www.legislation.qld.gov.au/ browse/inforce>.

Sayão, Luiz Fernando. 2010. "Uma outra face dos metadados: Informações para a gestão da preservação digital”. Encontros Bibli: Revista Eletrônica de Biblioteconomia e Ciência da Informação 15, n. 30: 1-31, <https://periodicos.ufsc.br/index. $\mathrm{php} / \mathrm{eb} / \mathrm{article} / \mathrm{view} / 12528>$.

Social Media Records in Austrália. 2017. "Archive Social”. Acessado em 10 de agosto de 2017, <http://archivesocial.com/social-media-records-australia>.

The American Council for Technology (ACT). 2011. "Best Practices Study of Social Media Records Policies”. Washington: ACT. Acessado em 10 de agosto de 2017, $<$ https://www.actiac.org/system/files/Best\%20Practices\%20of\%20Social\%20 Media\%20Records\%20Policies\%20-\%20CT\%20SIG\%20-\%2003-31-11\%20 $\% 283 \% 29 . p d f>$. 
The Obama White House-Social Media Archive. "Archive Social”. Washington, 2017. Acessado em 10 de agosto de 2017, <https://archivesocial.com/whitehouse/>.

United States Department of Justice (USDJ). 2016. The Freedom of Information Act. Washington. Acessado em 14 de agosto de 2018, <https://www.justice.gov/oip/ freedom-information-act-5-usc-552>.

Thomaz, K.P. e A.J. Soares. 2004. "A preservação digital e o modelo de referência Open Archival Information System (OASIS)". DataGramaZero 5, n. 1: 1-17. Acessado em 10 de agosto de 2017, <http://basessibi.c3sl.ufpr.br/brapci/_repositorio/2010/01/pdf_99df3bbc0d_000761>.

Thomson, Sara Day and Digital Preservation Coalition (DPC). 2016. "Preserving Social Media”. Digital Preservation Coalition 16, n. 1 (february): 1-37. Acessado em 10 de agosto de 2017, <https://www.dpconline.org/docs/technology-watch-reports/1486-twr16-01/file>.

Torres, C. 2009. A Bíblia do marketing digital: tudo o que você queria saber sobre o marketing e publicidade na internet e não tinh a quem perguntar. São Paulo: Novatec.

Tripathi, M. e S. Kumar. 2010. "Use of Web 2.0 Tools in Academic Libraries: A Reconnaissance of the International Landscape". The International Information E Library Review 42, n. 3: 195-207. Acessado em 10 de agosto de 2017, <http:// www.sciencedirect.com/science/article/pii/S1057231710000445>.

Uber. 2017. "A mobilidade que você deseja”. Página principal, São Paulo (website). Acessado em 10 de agosto de 2017, <https://www.uber.com/pt-BR/>.

ULCC e UKOLN. 2008. Preservation of Web Resources Handbook. Londres: ULCC/ UKOLN. Acessado em 10 de agosto de 2017, <http://www.jisc.ac.uk/publications/programmerelated/2008/powrhandbook.aspx>.

Unesco. 2012. "A memória do mundo na era digital: digitalização e preservação". Vancouver: Unesco. Acessado em 10 de agosto de 2017, <http://www.unesco. org/new/fileadmin/MULTIMEDIA/HQ/CI/CI/images/mow/unesco_ubc_vancouver_declaration_pt.pdf $>$.

Unesco. 2003. "Charter on the Preservation of the Digital Heritage”. París. Acessado em 10 de agosto de 2017, <http://www.unesco.org/new/fileadmin/MULTIMEDIA/HQ/CI/CI/pdf/mow/charter_preservation_digital_heritage_en.pdf $>$.

United Kingdom Government Web Archive (ukgwa). Nd. "National Archives”. Richmond (website). Acessado em 10 de agosto de 2017, <http://www.nationalarchives.gov.uk/webarchive/>.

Waze. 2017. “Sobre Nós”. Acessado em 10 de agosto de 2017, <https://www.waze. com/pt-BR/about>.

Wikipedia. 2017. "Bem-vindos à Wikipédia: A enciclopédia livre que todos podem editar”. Página principal. Última modificação: 15 de agosto de 2017, <https:// pt.wikipedia.org/wiki/Wikip\%C3\%A9dia:P\%C3\%A1gina_principal>.

Para citar este texto:

Rodrigues Rezende, Laura Vilela y Dalton Lopes Martins. 2019. "Experiências e desafios para a preservação digital de mídias sociais". Investigación Bibliotecológica: archivonomía, bibliotecología e información 33 (80): 31-56. http://dx.doi.org/10.22201/iibi.24488321xe.2019.80.57962 